Ben Richard Hughes, Michael Oates, Performance investigation of a passive solar-assisted kiln in the United Kingdom, Solar Energy, Volume 85, Issue 7, July 2011, Pages 1488-1498, ISSN 0038-092X, http://dx.doi.org/10.1016/j.solener.2011.04.003.

\title{
Performance investigation of a passive solar-assisted kiln in the United Kingdom
}

Dr Ben Richard Hughes: Heriot-Watt University Dubai Campus, School of Engineering and Physical Sciences, Block 2 Dubai International Academic City, PO Box 294345, Dubai, United Arab Emirates

Michael Oates: Mechanical Engineering Research Program, Sheffield Hallam University, Faculty of Arts, Computing, Engineering and Sciences, Materials and Engineering Research Institute, Sheffield, South Yorkshire, United Kingdom, S1 1WB.

Keywords: - CFD, buildings, solar kiln, natural ventilation, sustainable resources

\begin{abstract}
Solar kilns have been existence for many years in various forms. Recently the advent of increased energy costs has led to new low energy solar powered technologies being incorporated to kiln designs to enhance their performance capabilities. However before applying new technologies it is necessary to investigate the basic kiln design. The basic kiln design is considered for the temperate climate of the United Kingdom (UK), using Computational Fluid Dynamics, validated through experimental investigation. This investigation considers whether the basic kiln design is adequate for the UK climate, with respect to sunshine hours and temperature. key performance indicators of the kiln namely overall heat loss, air flow and temperature distribution, are analysed and reported here. The results of this work found that the low heat loss of the kiln highlights enormous potential of the lightweight structure to optimise the suns potential within a temperate climate such as the UK. Moreover the basic design is modified to demonstrate the effect of introducing natural ventilation strategies to the kiln and their effect on performance.
\end{abstract}




\subsection{Introduction}

The basic use of a kiln exists in the form of drying ceramics and wood. Kilns are also used in developing countries to dry coffee beans and other agricultural products. It is reported that there are over 400 types of dryers with 100 types of dryers more commonly available (Mujumdar and Arun, 2006). Kilns have been developed to use fossil fuel to source heat directly through natural gas, electricity, oil and indirectly through steam and heat exchangers. The use of renewable energy is becoming more common due to the high energy usage required to generate heat. Typically, conventional wood drying kilns are highly energy intensive, depending on the wood type and thickness conventional dryers range from 600 to $1000 \mathrm{kWhm}^{-3}$ (Mujumdar and Arun, 2006).. The rising price of fossil fuels is also driving the use of renewable energy to ensure the final kiln dried products remain competitive within the market. Conventionally wood drying kilns are traditionally convection dryers with $85 \%$ of industrial dryers being the type of with hot air or direct combustion gases as the drying medium (Mujumdar and Arun, 2006).. Other methods consist of solvent drying, infra-red drying, high frequency drying, microwave drying, superheated steam drying, and chemical seasoning using salts (Haque 2002).

Recent work has highlighted the potential of solar drying techniques for food and crop drying drying (Devore et al.1999, Chen et al. 2005, Hossain and Bala 2007, Jairaj et el. 2009, Sethi and Arora 2009). The main focus of this work concentrates on a non mechanical solar passive wood drying kiln within the United Kingdom (UK) climate. Wood drying is a necessary process of reducing the moisture content in sawn timber to a condition at which the wood will operate in normal service conditions. This process ensures that shrinkage and moisture change occurs before the wood is used for manufacture, and therefore dimensional changes once in use are kept to a minimum. The use of solar power is free and can achieve excellent results for a kiln once designed correctly. The integration of this technology will contribute to reducing carbon emissions. Free solar powered energy can be optimised by eco-villages for use of drying firewood and forestry's where limited energy supplies exist.

\subsection{Previous related work}

Ferreira et al. 2008, presented a feasibility assessment of a solar chimney device for the application of food drying. The work developed and tested in a full scale prototype in brazil which demonstrated the capabilities of solar drying for the selected application. 
Forson et al. 2007, developed a mixed mode solar crop drying device using mathematical and experimental modelling. The work used a single pass double duct solar air heater for the experimental work and was used to develop a design methodology for prototype development.

Bentayeba et al. 2008, presented a numerical simulation of the function of a solar kiln and show the numerical results have good agreement with experimental results taken from the wood solar kiln. This paper shows that numerical principles can be applied to correctly estimate actual performance.

Fuwape and Fuwape 1995, investigated the use of a solar kiln to improve timber quality and reduce the drying process time in relation to air dried timber processes used in developing countries. The paper highlights the importance of drying timber to the optimum condition through the use of a controlled environment to ensure that a higher quality of seasoned timber is produced.

Hughes and Ghani 2008, investigated a passive ventilation device, the windvent, and evaluated its performance against UK guidelines using CFD software. This work showed the potential of CFD for investigating natural ventilation performance device.

Luna et al. 2009 reviewed the evolution in solar heated drying kilns. The work summarises developments made to solar timber drying kilns in the past decade and proposes potential future developments.

However the UK climate is not considered viable for solar kilns in purely passive form. Thus several technical innovations have been used to improve efficiency of solar kilns in the UK. This study benchmarks a standard passive solar kiln to determine its performance with respect to the UK climate. Moreover this work introduces natural ventilation techniques to optimise the design and analyse the effects on performance.

\subsection{Benchmark Solar Kiln}

The solar kiln used as the focus of this investigation is shown in Figure 1. The timber framed kiln has one airflow inlet; solar induced, at ground level, with three airflow exits at roof level, directed via an aluminium canopy. Overall internal dimensions of the structure are $3.38 \mathrm{x}$ $2.17 \times 2.22 \mathrm{~m}(\mathrm{I} \times \mathrm{b} \times \mathrm{h})$. The internal canopy is fixed in position (height) using chains dependant on the load to be dried. Overall canopy dimension are $3.0 \times 1.39 \times 0.46 \mathrm{~m}$ with 
cylindrical outlets of $0.22 \mathrm{~m}$ diameter. The numerical investigation used the internal dimensions to represent the physical geometry [Figure 1 (b)] with wall thickness and material properties assigned directly in the solver.

a)

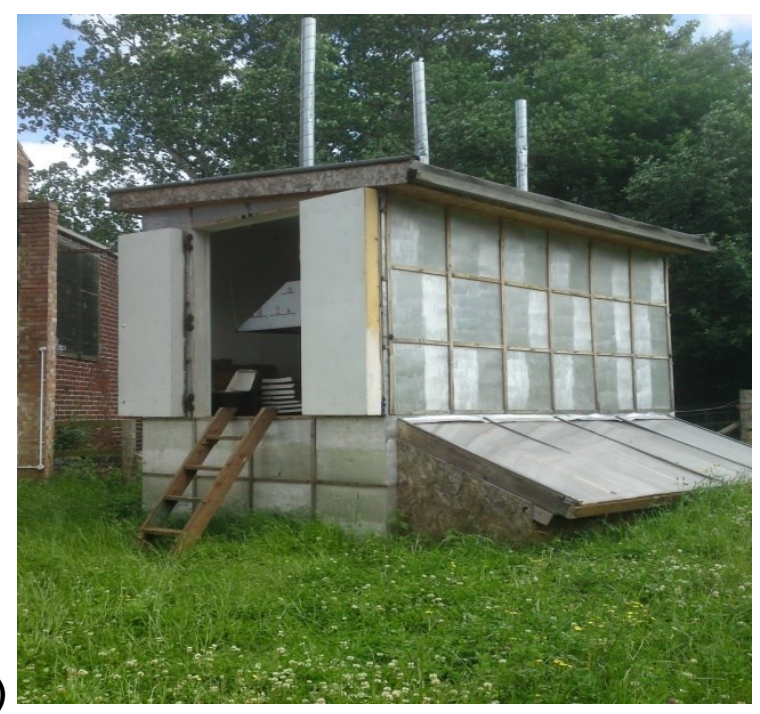

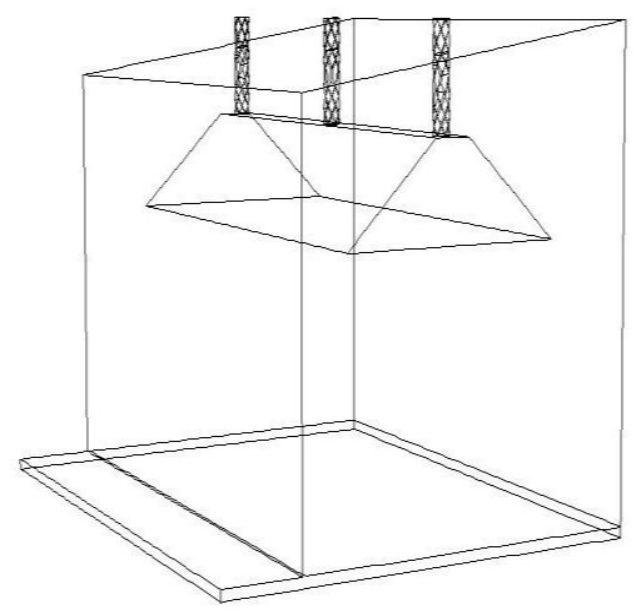

b)

Figure 1 - Visual representation of a solar powered kiln a) Existing solar powered Kin, b) CFD model

\subsection{CFD Model set up}

The CFD model was developed using FLUENT, a commercially available general-purpose code. This code uses the finite volume method approach and employs the Semi-Implicit Method for Pressure-Linked Equations Consistent (SIMPLEC) velocity-pressurecoupling algorithm. The turbulent nature of the flow is modelled by the k-e RNG model. The simulation solution control used was the PRessure-Staggered Option (PRESTO!) which is the most suitable for low velocity natural ventilation flow, with second order upwind accuracy for all equations. The governing equations are the well known Navier-Stokes and Energy equations which will not be repeated here but are available in detail in Fluent 2006. Simple boundary conditions were used for the air inlet (velocity inlet) and air outlet (pressure outlet) applied at the pre-processing stage (Gambit). Material properties and operating conditions were applied directly to the solver (Fluent) and detailed in Table 1. 
Table 1 - Fluent operating and boundary conditions

\begin{tabular}{|l|l|}
\hline \multicolumn{2}{|l|}{ Operating and Boundary Conditions } \\
\hline User Input & Value \\
\hline Inlet Velocity & $1.5 \mathrm{~m} / \mathrm{s}$ \\
\hline Output Pressure & $0 \mathrm{~Pa}$ Gauge Pressure \\
\hline Backflow total temperature & $303^{\circ} \mathrm{K}$ \\
\hline Gravity & On, and to -9.81 vertically \\
\hline Inlet Temperature & $303^{\circ} \mathrm{K}$ \\
\hline Wall thermal conditions & Set to convection \\
\hline Wall Material & Wood (Aluminium for canopy) \\
\hline Wall free stream temperature & $288^{\circ} \mathrm{K}$ (Outside air temp) \\
\hline Wall heat transfer coefficient & $10 \mathrm{w} / \mathrm{mK}$ \\
\hline Wall thickness & $0.20 \mathrm{~m}$ \\
\hline Fluid & Air \\
\hline
\end{tabular}

A supplementary face was created as a complete vertical cross-section through the computational domain. This face is used as a post processing tool to illustrate the calculated thermal and velocity contour plots.

\subsection{Grid Verification}

In order to accurately resolve the solution fields, the grid was refined and enriched using $h p$ methods (Chung 2002). This process of adaption requires a decision as to the usage of $h$ refinements (the mesh size) or $p$-enrichments (higher order approximations) by the use of a posteriori error estimate. The posteriori estimate used in the developed model is the average weighted velocity taken at the pressure outlets. The initial coarse grid was evaluated, and subsequent refinements were evaluated until the error deemed negligible between refinements shown in Table 2.

Table 2 - Posteriori error table

\begin{tabular}{|c|c|c|c|c|c|c|c|c|c|}
\hline & & \multicolumn{4}{|c|}{ TYPE OF ELEMENT } & \multicolumn{2}{|c|}{ Iteration } & & \\
\hline $\begin{array}{l}\text { No. of } \\
\text { Elements }\end{array}$ & $\begin{array}{l}\text { Size of } \\
\text { Elements }\end{array}$ & Elements & $\begin{array}{c}\text { No. of nodes } \\
\text { per element }\end{array}$ & Type & Smoother & $\begin{array}{c}\text { No. of } \\
\text { Iteration }\end{array}$ & $\begin{array}{c}\text { Converged } \\
@\end{array}$ & $\begin{array}{c}\text { Weighted Average } \\
\text { Velocity (m/s) }\end{array}$ & $\begin{array}{c}\text { Difference } \\
(\%)\end{array}$ \\
\hline 27300 & 0.10 & HEX & 8 & Map & None & 1000 & 633 & 0.371 & 0 \\
\hline 36333 & 0.090 & HEX & 8 & Map & None & 1000 & 808 & 0.375 & 1.05 \\
\hline 64560 & 0.075 & HEX & 8 & Map & None & 2000 & 1920 & 0.389 & 4.46 \\
\hline 100924 & 0.065 & HEX & 8 & Map & None & 1000 & 849 & 0.396 & 6.24 \\
\hline 218400 & 0.05 & HEX & 8 & Map & None & 2000 & 1653 & 0.378 & 1.82 \\
\hline
\end{tabular}

The mesh sizes that are not a perfect division of the inlet and outlet are forced into the geometry of the kiln causing errors and numerical instability; this can be seen for a mesh of $0.065 \mathrm{~m}$ with an error of $6.24 \%$ in relation to the base line mesh of $0.1 \mathrm{~m}$. The element size at 0.05 with an error of $1.84 \%$ produced optimum result accuracy. The standard 8 nodes per hexahedron are adequate for this analysis. The 8 nodes calculate implicit results at the 
corner and centre point between nodes for the hexahedron element. Higher approximations such as 20 or 24 nodes provided no notable variation in the posterior error indicator.

\subsection{Validation}

The simulation results have been validated through systematic field measurement. The equipment used was a Testo 435-4 meter with a hotwire thermal velocity probe. The meter when connected to the velocity probe, took a time-averaged sample of the velocity (three minutes), and was compares to a user defined internal volume of the kiln to give a definitive reading. The probe gives both velocity and temperature data through the meter over the same sample period with a manufacturer stated accuracy of $0.15 \%$. Twelve points were taken both inside and outside the solar kiln and a direct comparison made with the CFD model, location of the internal points are shown in Figure 2, the inlet was sampled centrally (In terms of width and height) and the two outlets either side of centre were used as the external measurements.

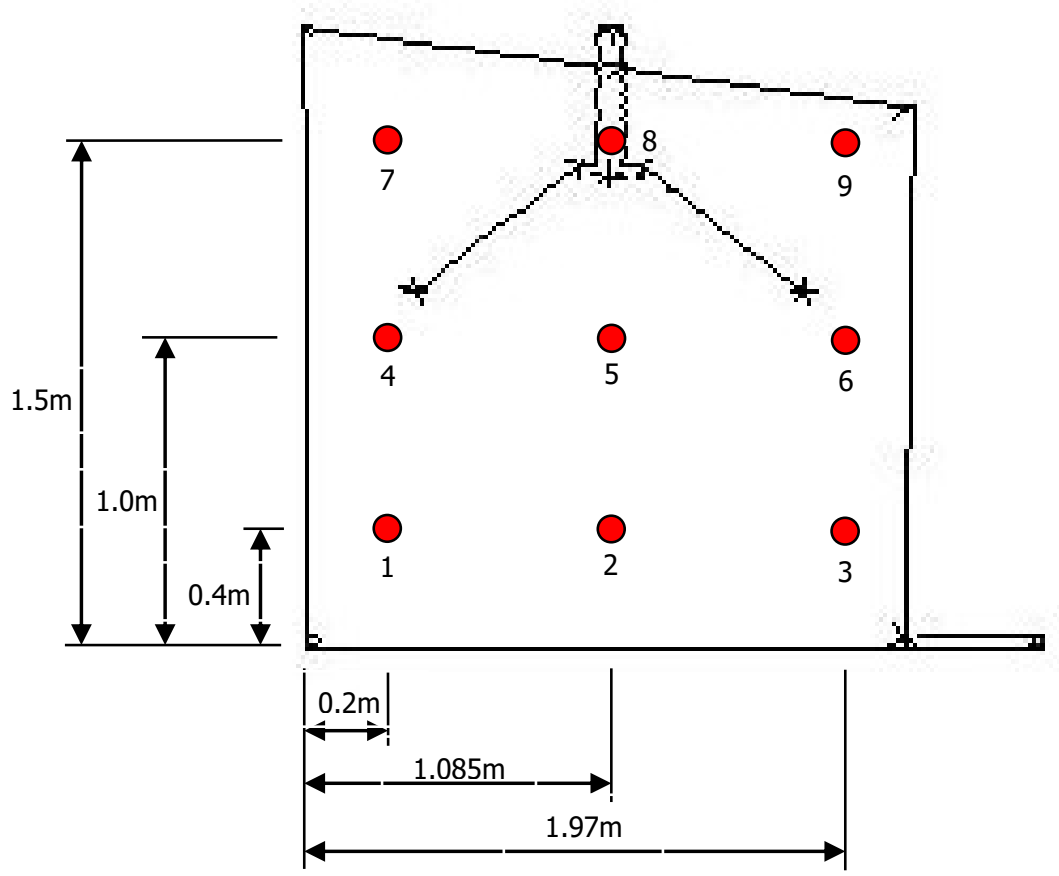

\begin{tabular}{|c|c|}
\hline Point & Temperature $\left({ }^{\circ} \mathrm{C}\right)$ \\
\hline 1 & 26.3 \\
\hline 2 & 25.6 \\
\hline 3 & 29.8 \\
\hline 4 & 26.8 \\
\hline 5 & 25.3 \\
\hline 6 & 25.9 \\
\hline 7 & 26.9 \\
\hline 8 & 27.1 \\
\hline 9 & 26.5 \\
\hline
\end{tabular}

Figure 2 Location of the internal sample points for validation purposes, cross section (Half breadth of kiln).

The comparison of the CFD results and experimental readings are shown in Figure 3 . The actual sampled inlet velocity measure was $0.55 \mathrm{~m} / \mathrm{s}$, thus the CFD simulation was run at this inlet speed for the purpose of validation only to enable a direct comparison. 


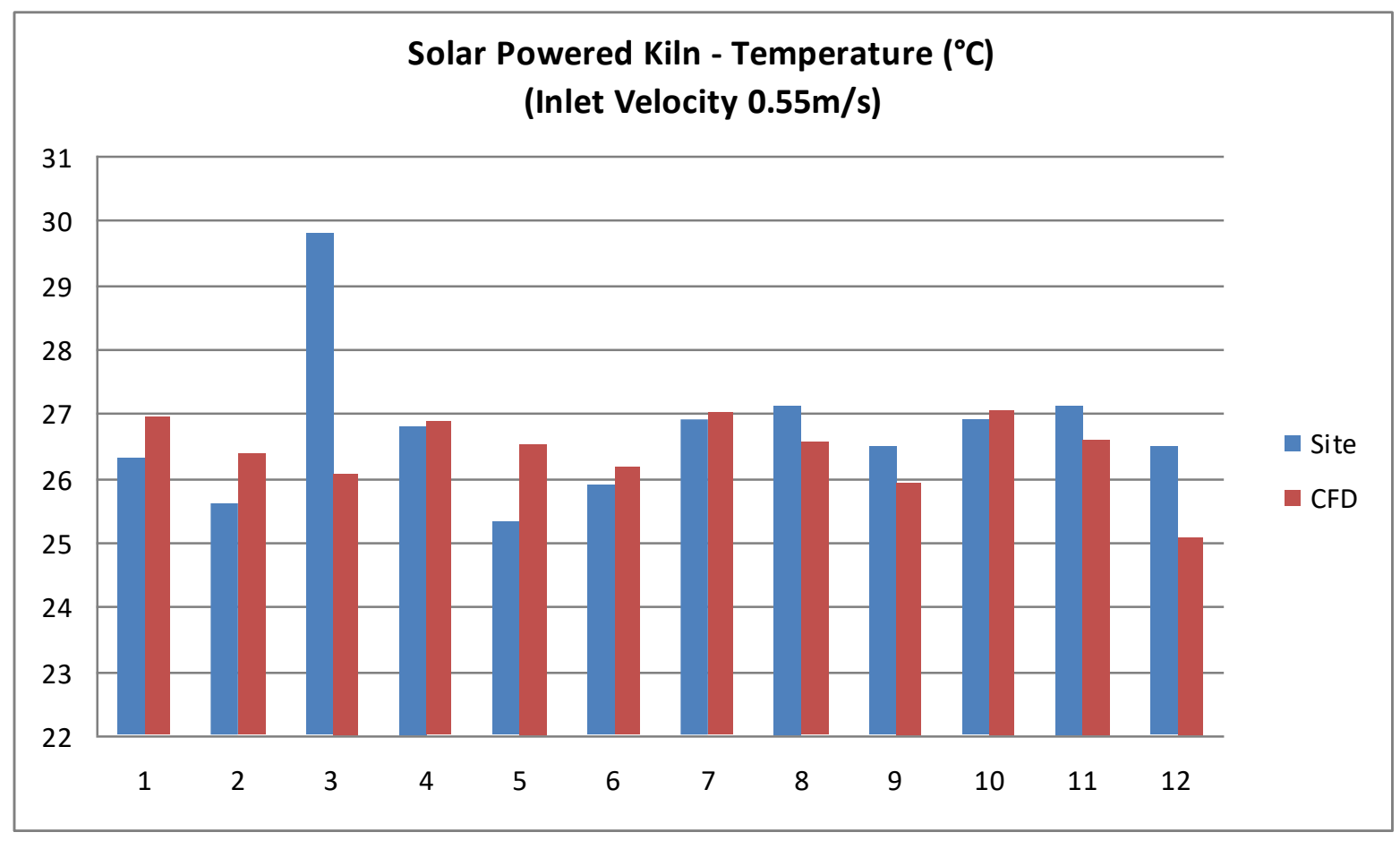

Figure 3 Validation of benchmark solar kiln CFD model against experimental data

It is clearly seen that both the trend and values are in good agreement, with most points showing a difference of within 1 degree celcius between the CFD model and the experimental measurement. A further comparison was drawn between the velocity measurements taken from the same points with an inlet velocity of $0.55 \mathrm{~m} / \mathrm{s}$ to remain consistent with the temperature comparison, these results are shown in figure 4 . 


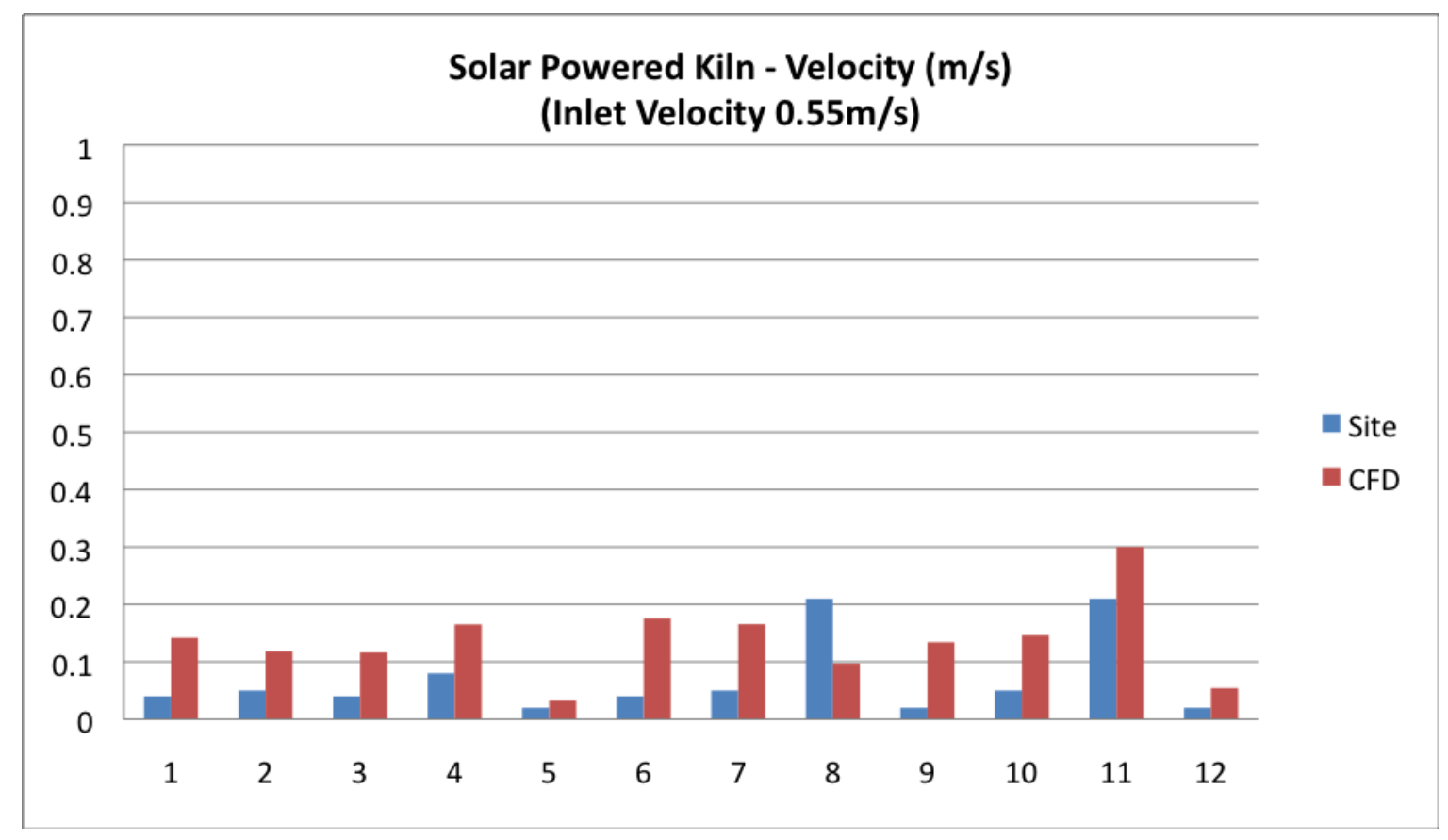

Figure 4 Validation of bencjmark kiln CFD model against experimental data

From the results it is see that the trend and values are in agreement at all points with the. The difference between the CFD and experimental is less than $0.1 \mathrm{~m} / \mathrm{s}$ at most points. Hence the model was validated (Jiang et al. 2004). Having achieved a valid CFD model modifications were carried out based on previous work (Lomas 2007) to optimise the performance of the kiln, shown in Figure 5.
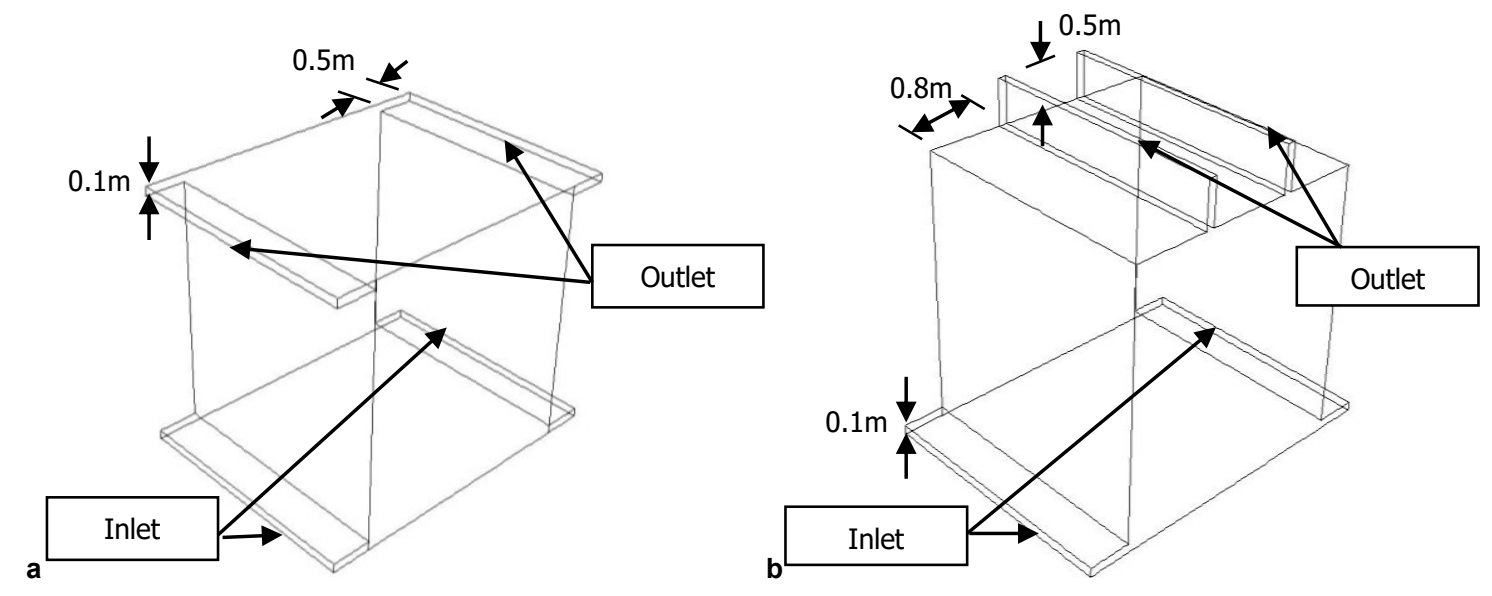

Figure 5 Modified kiln a) cross ventilation, b) cross ventilation with roof extract 


\subsection{Results}

The key performance indicators for the solar kiln are temperature and velocity. The temperature is used to extract the moisture from the material. The velocity creates evenly distributed movement around the load to aid extraction of the moisture to atmosphere.

\subsection{Airflow distribution within the kiln}

The benchmark kiln results for the airflow path Figure 6 show the velocity entering at ground level, sweeping across the floor area before being sheared vertically by the opposing wall. The flow is then redirected horizontally via the roof face before being sheared vertically towards the ground. Finally the flow is drawn towards the canopy exits.
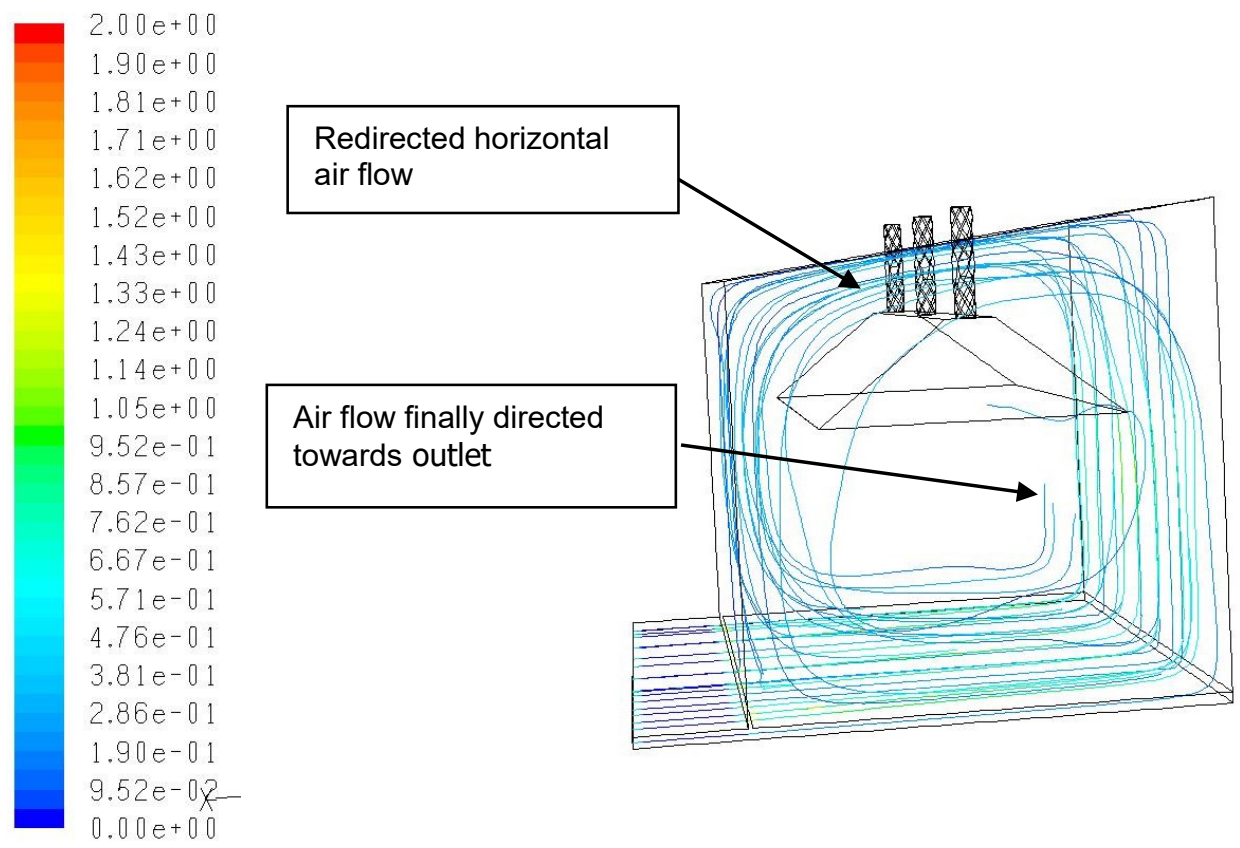

Figure 6 - Pathlines coloured by velocity magnitude $(\mathrm{m} / \mathrm{s})$

The velocity results Figure 7 , shown as contours, illustrate the rate of air circulating within the structure. The velocity is drawn in across the floor and dissipates as it shears across the internal wall geometry, before increasing upon exit through the outlet nozzle area. 


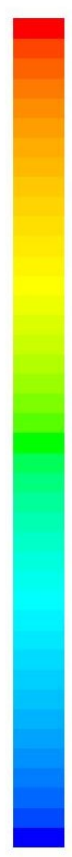

$2.00 e+00$

$1.90 e+00$

$1.81 e+00$

$1.71 e+00$

$1.62 e+00$

$1.52 e+00$

$1.43 e+00$

$1.33 e+00$

$1.24 e+00$

$1.14 e+00$

$1.05 e+00$

$9.52 e-01$

$8.57 e-01$

$7.62 e-01$

$6.67 e-01$

$5.71 e-01$

$4.76 e-01$

$3.81 e-01$

$2.86 e-01$

$1.90 e-01$

$9.52 e-0 x$

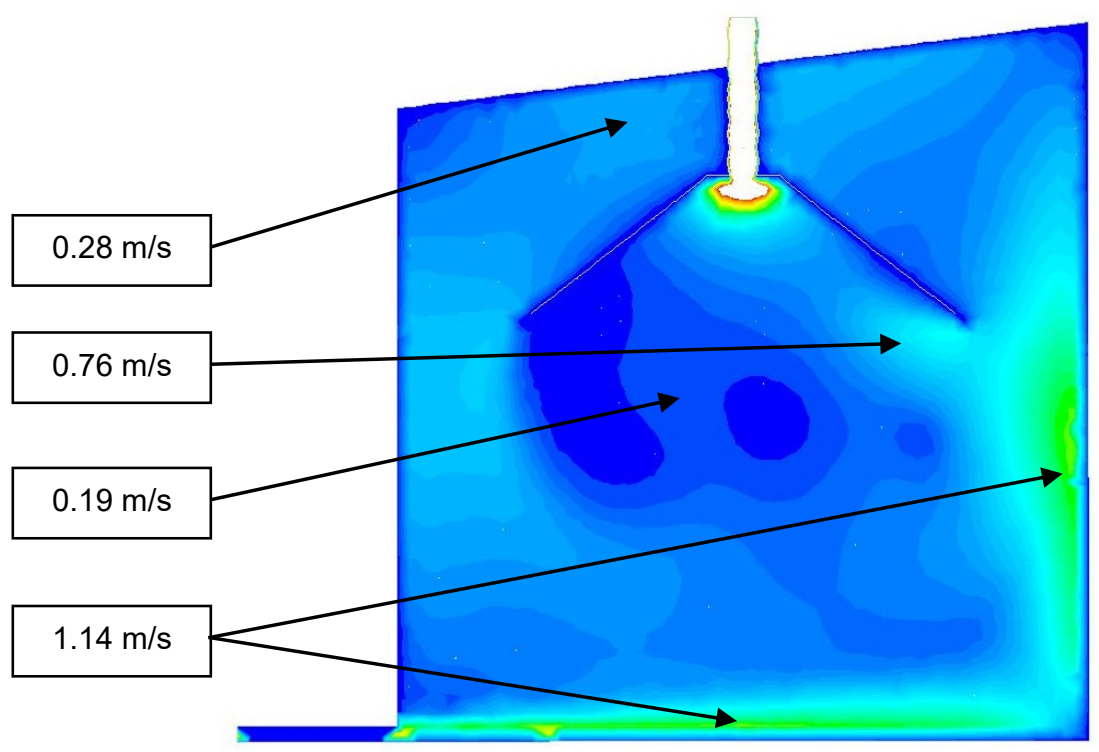

$0.00 e+00$

Figure 7 - Contours of velocity magnitude $(\mathrm{m} / \mathrm{s})$

The temperature results Figure 8, shown as contours, follow the same route as the airflow and velocity. Maximum velocity is evident on the floor and opposing wall geometry.

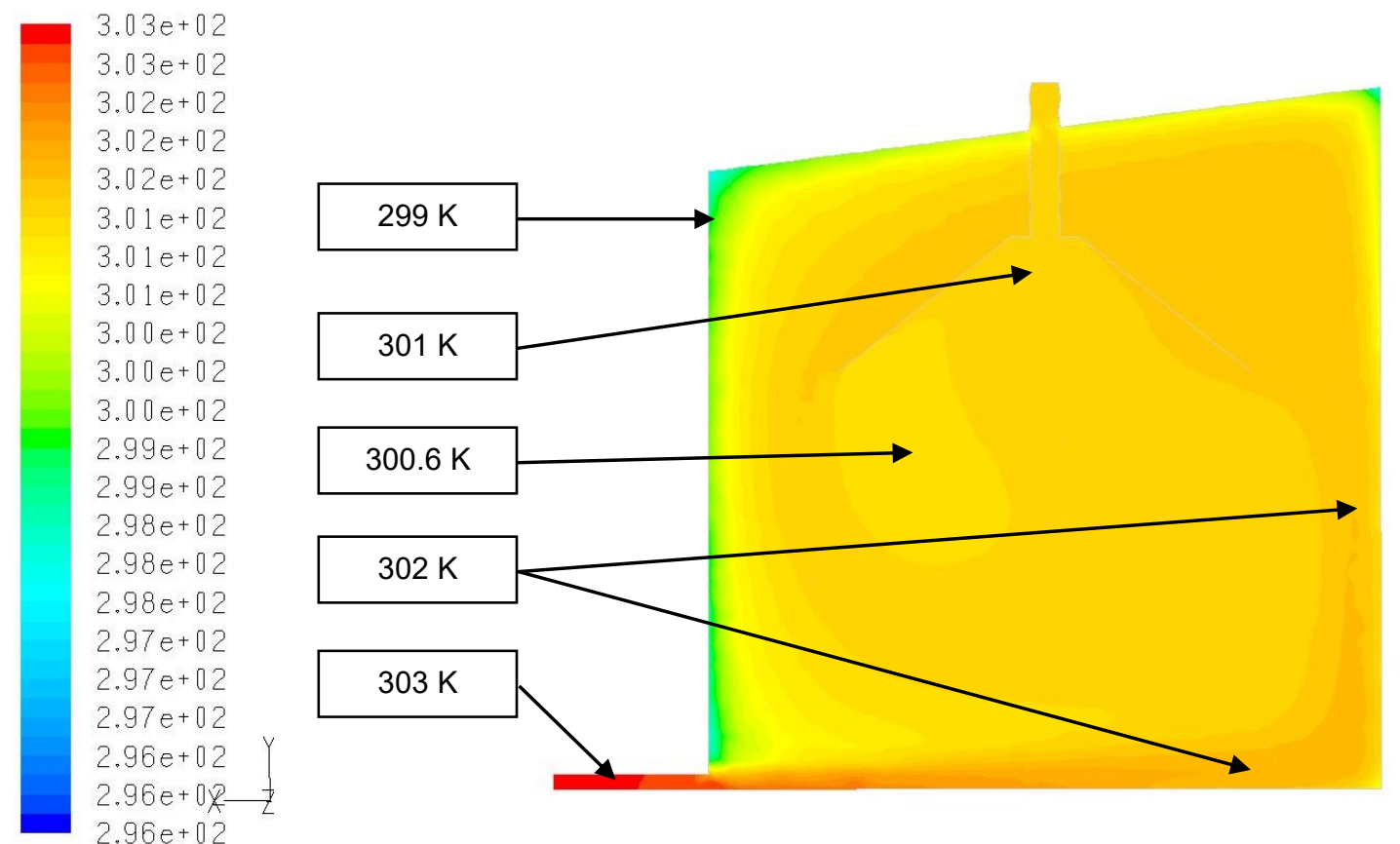

Figure 8 - Contours of total temperature (K) 


\subsection{Heat loss within the kiln}

In order to perform the simulations, assumptions must be made for the input parameters, the following describes the rationale for the assumptions. The heat loss of the kiln relates to the parameters of the model highlighted in Table 1 (i.e. inlet temperature 303K and external air temperature 288K). The lightweight structure of the kiln shall be significantly affected by convection losses on the internal and external wall perimeters of the kiln. In relation to heat loss, conduction losses shall be minimal in contrast to the convection losses. The CFD simulations show a heat loss of 1517W per unit depth.

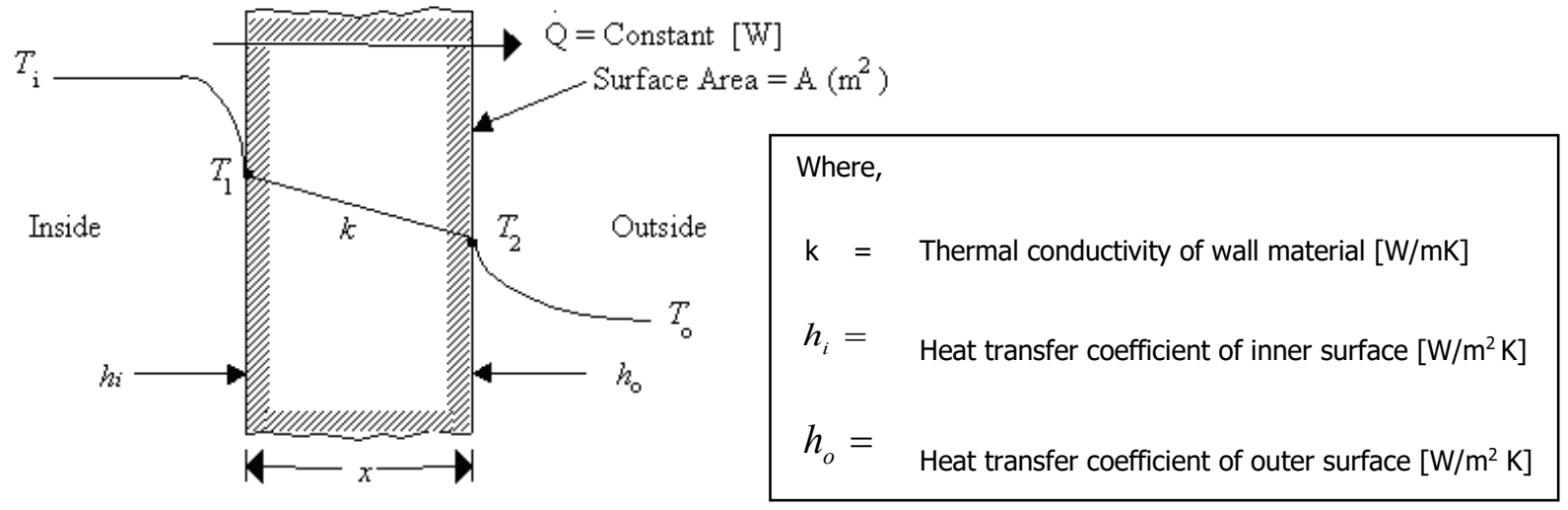

Figure 9 - Heat transfer through a plane wall

At Ti to T1 the heat transfer is by convection, same at T2 to T0. Between T1 to T2 the heat transfer is by conduction. The total heat transfer is equated from Newton's law of convection and Fourier's law of conduction, shown below:

$\dot{Q}=U A \Delta T\left(\mathrm{~W} / \mathrm{m}^{2} \mathrm{~K}\right)$

where,

$\frac{1}{U}=\frac{1}{h_{i}}+\frac{x}{k}+\frac{1}{h_{o}}$

The CFD model assumed that the thermal boundary conditions for the wall are set for convection (i.e. convection losses are higher than conduction, conduction losses are considered negligible for this type of lightweight structure analysis). The internal convection of the air is caused by the flow of the inlet air, therefore the calculation must consider 
convection on the internal surface. Due to the changing air flow velocity throughout the kiln the internal and external convection parameters are considered the same for this calculation.

$$
\begin{aligned}
& \frac{\dot{Q}}{A}=\left(\frac{1}{\frac{1}{h_{i}}+\frac{x_{2}}{k_{2}}+\frac{1}{h_{0}}}\right)\left(T_{2}-T_{1}\right) \quad \therefore \quad \frac{\dot{Q}}{1}=\left(\frac{1}{\frac{1}{10}+0+\frac{1}{10}}\right)(288-303) \\
& \dot{Q}=\frac{1}{0.1} \times-15 \\
& \dot{Q}=-75 \text { W per unit depth (1m). (i.e. negative meaning loss) }
\end{aligned}
$$

The total heat loss of the $3.38 \times 2.17 \times 2.22 \mathrm{~m}(\mathrm{l} \times \mathrm{b} \times \mathrm{h})$ kiln equates to $1221 \mathrm{~W}$ (i.e. $(3.38 \times 2.17 \times 2.22) \times-75)$, which is in a similar area to the heat loss of the kiln through CFD analysis.

\subsection{Meteorological data for the UK (Sheffield)}

Table 3 - Meteorology Office Historical Weather Station Recordings (Sheffield 2008)

\begin{tabular}{|c|c|c|c|c|c|c|}
\hline Year & month & $\begin{array}{c}\text { tmax } \\
(\text { degC })\end{array}$ & $\begin{array}{c}\text { tmin } \\
(\mathbf{d e g} \mathbf{C})\end{array}$ & $\begin{array}{c}\text { Air } \\
\text { frost } \\
(\text { days })\end{array}$ & $\begin{array}{c}\text { rain } \\
(\mathbf{m m})\end{array}$ & $\begin{array}{c}\text { sun } \\
(\text { Hrs })\end{array}$ \\
\hline 2008 & 1 & 9 & 3.9 & 2 & 154 & 43.6 \\
\hline 2008 & 2 & 9.1 & 1.4 & 9 & 48.7 & 121.2 \\
\hline 2008 & 3 & 9.1 & 2.7 & 3 & 98.8 & 137.8 \\
\hline 2008 & 4 & 11.4 & 4.4 & 2 & 79.2 & 126.8 \\
\hline 2008 & 5 & 17.5 & 8.6 & 0 & 43.5 & 186.7 \\
\hline 2008 & 6 & 18.7 & 10.7 & 0 & 56.7 & 198.1 \\
\hline 2008 & 7 & 20.8 & 13 & 0 & 108.7 & 202.6 \\
\hline 2008 & 8 & 20.1 & 13.4 & 0 & 82.6 & 141.1 \\
\hline 2008 & 9 & 17.0 & 10.8 & 0 & 92.4 & 105.6 \\
\hline 2008 & 10 & 12.8 & 7.2 & 0 & 93.2 & 120.2 \\
\hline 2008 & 11 & 9 & 4.9 & 3 & 60 & 54.9 \\
\hline 2008 & 12 & 6.1 & 2.2 & 4 & 52.8 & 67.2 \\
\hline
\end{tabular}


Having established the capabilites of the benchmark kiln a design optimisation was carried out to determine the optimum airflow strategy to deliver the best performance in the UK based in the standard design and natural ventilation techniques.

\subsection{Modified design a) Cross-ventilation kiln}

Figure 10 illustrates the air flow path of the cross ventilated kiln. The airflow of the two inlets along the horizontal ground plane drives the airflow horizontally through the centre of the kiln. The horizontal flow is then redirected vertically along the roof of the kiln towards the two opposite outlets. Airflow that is not exhausted to atmosphere is redirected along the perimeter edge and recirculated again.

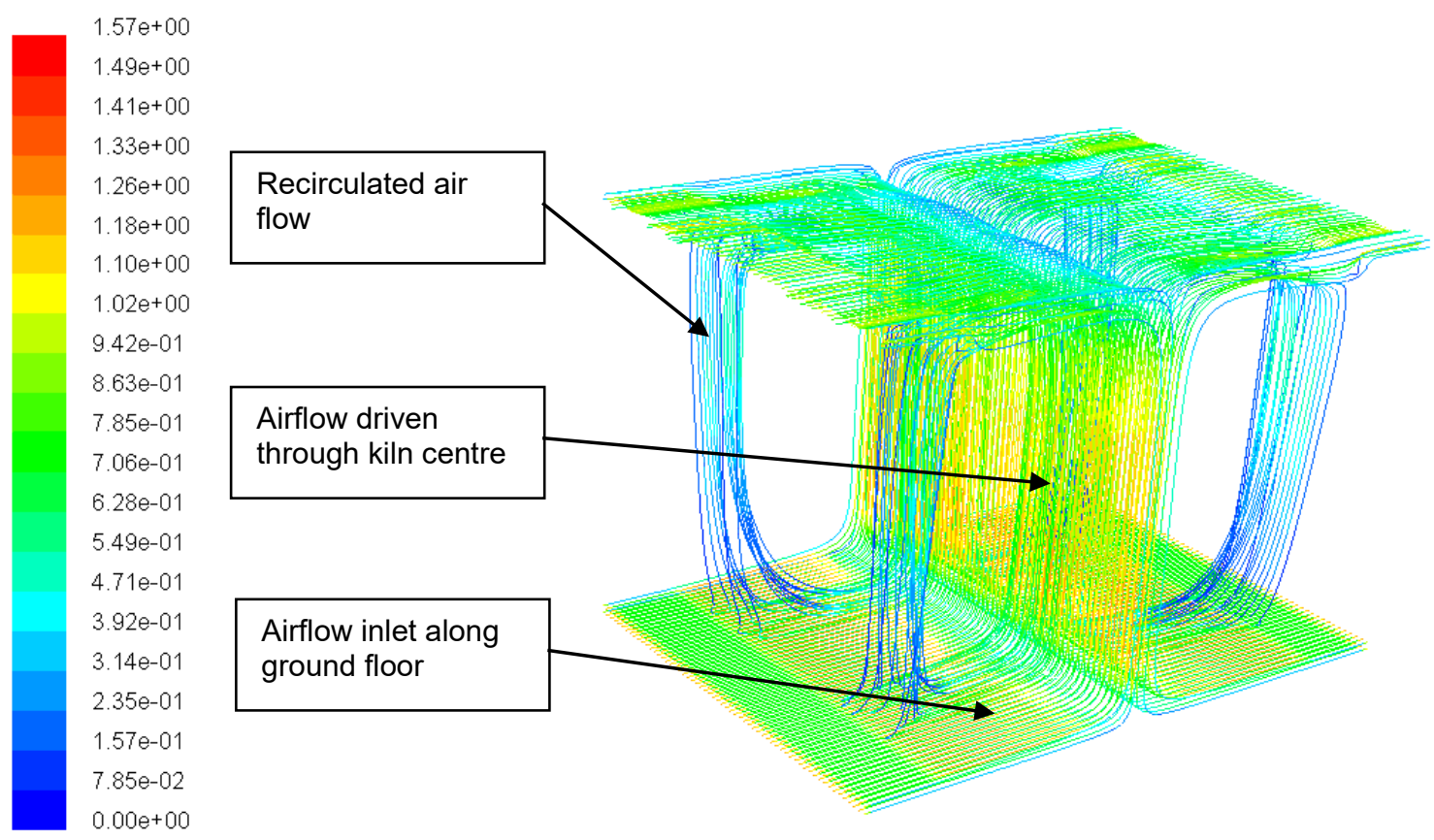

Figure 10 - Pathlines coloured by velocity magnitude $(\mathrm{m} / \mathrm{s})$

The velocity results Figure 11, highlight the central airflow pattern through the core of the kiln. The airflow is drawn across the ground floor, through the centre and along the roof to the outlets. The airflow travels at a lower velocity at either side of the central airflow path. 


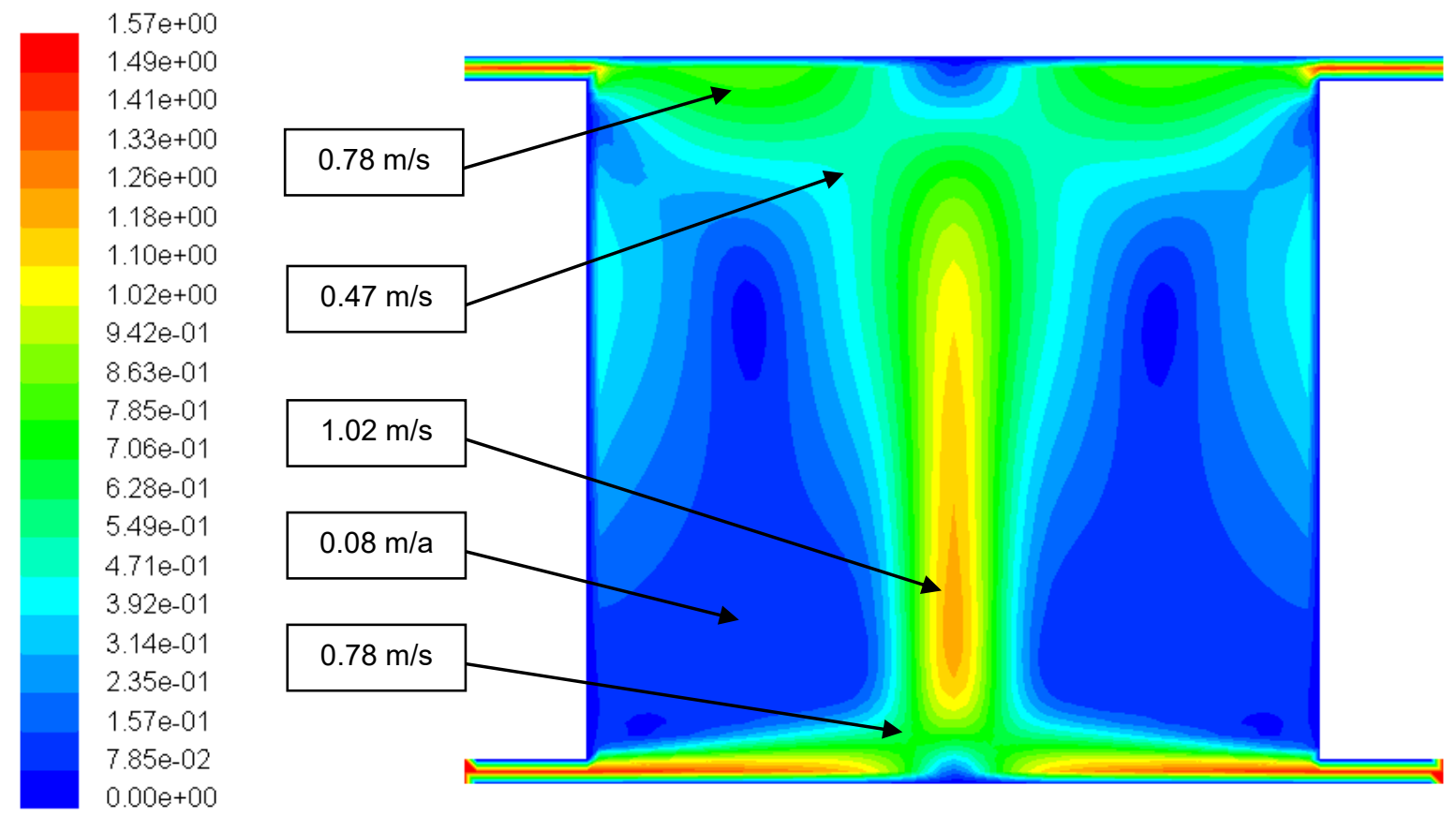

Figure 11 - Contours of velocity magnitude $(\mathrm{m} / \mathrm{s})$

The temperature results Figure 12, shown as contours, follow the same route as the airflow and velocity. Maximum temperature flows through the centre of the kiln and horizontal towards the two opposite outlets.
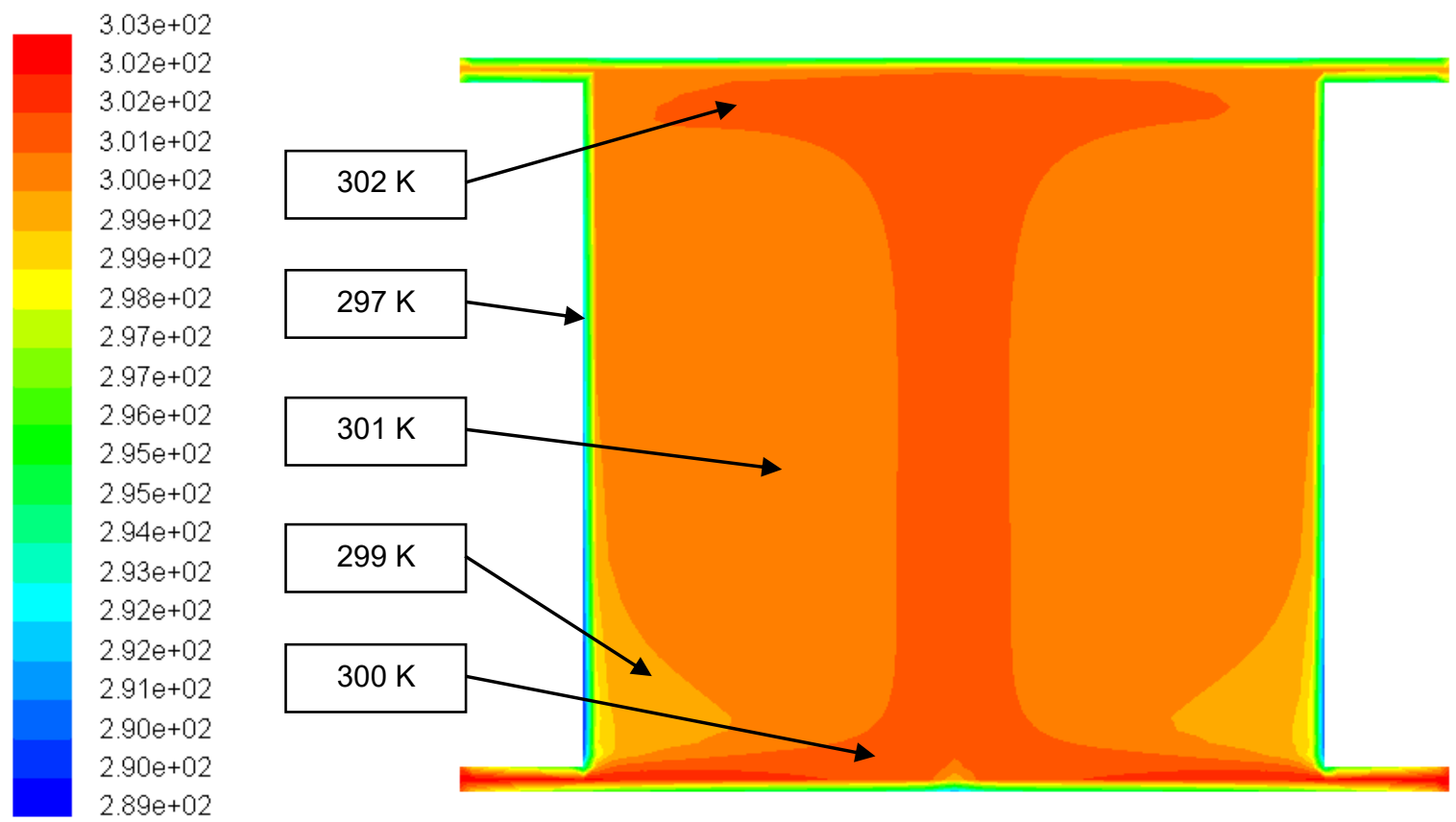

Figure 12 - Contours of total temperature (K) 


\subsection{Modified design b) Cross ventilation with roof extract kiln}

The airflow path of the double sided ventilated kiln with two vertical top outlets is shown in Figure 13. The airflow is driven along the ground and through the centre of the kiln. The airflow is then drawn towards the two outlets symmetrical positioned on the roof.
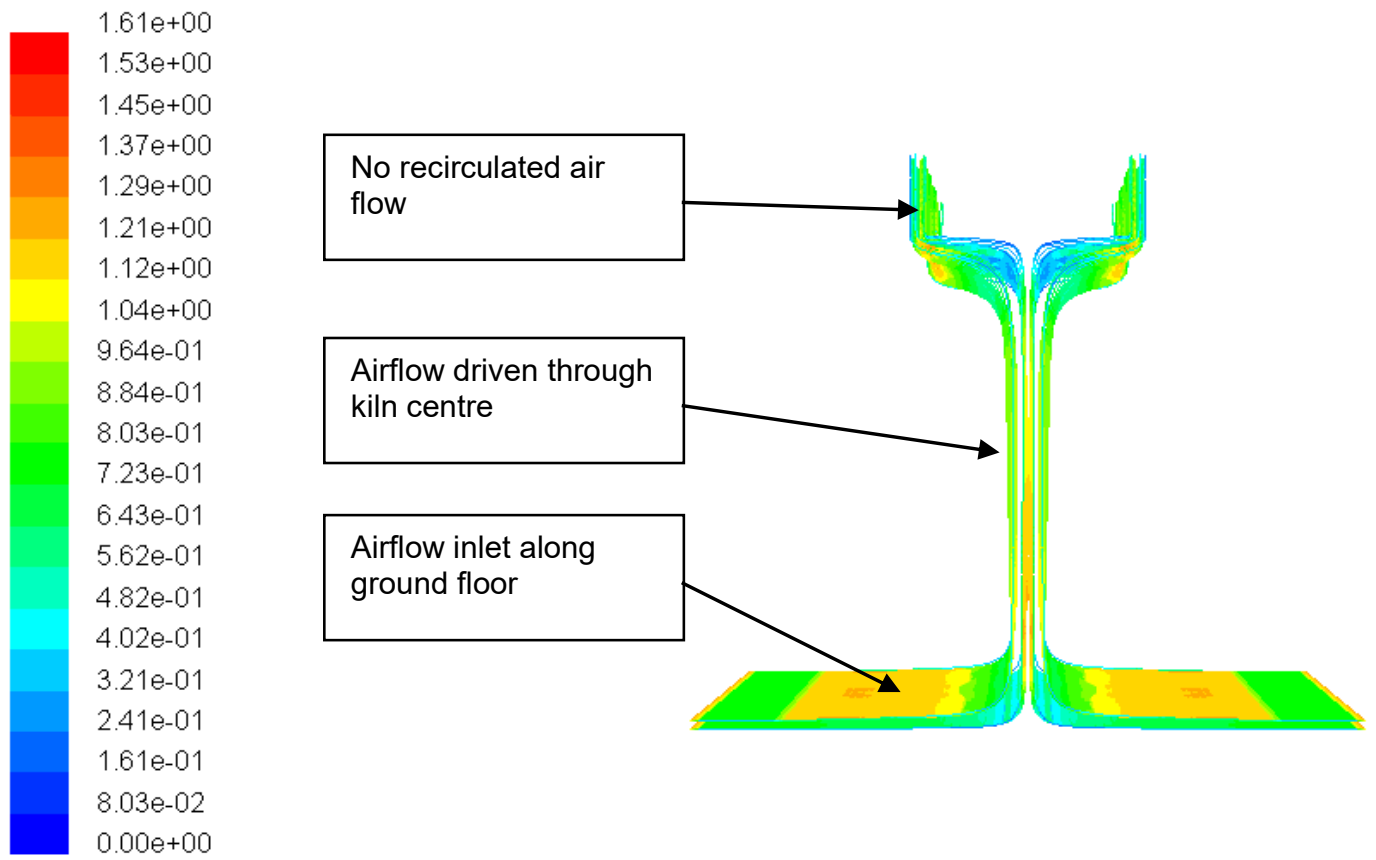

Figure 13 - Pathlines coloured by velocity magnitude $(\mathrm{m} / \mathrm{s})$

The velocity results Figure 14, highlight the central airflow pattern through the core of the kiln. The airflow is drawn across the ground floor, through the centre and direrctly towards the outlets. Due to the air flow pattern, the air flow recirculates at a lower velocity at either side of the kiln than at the central core. 

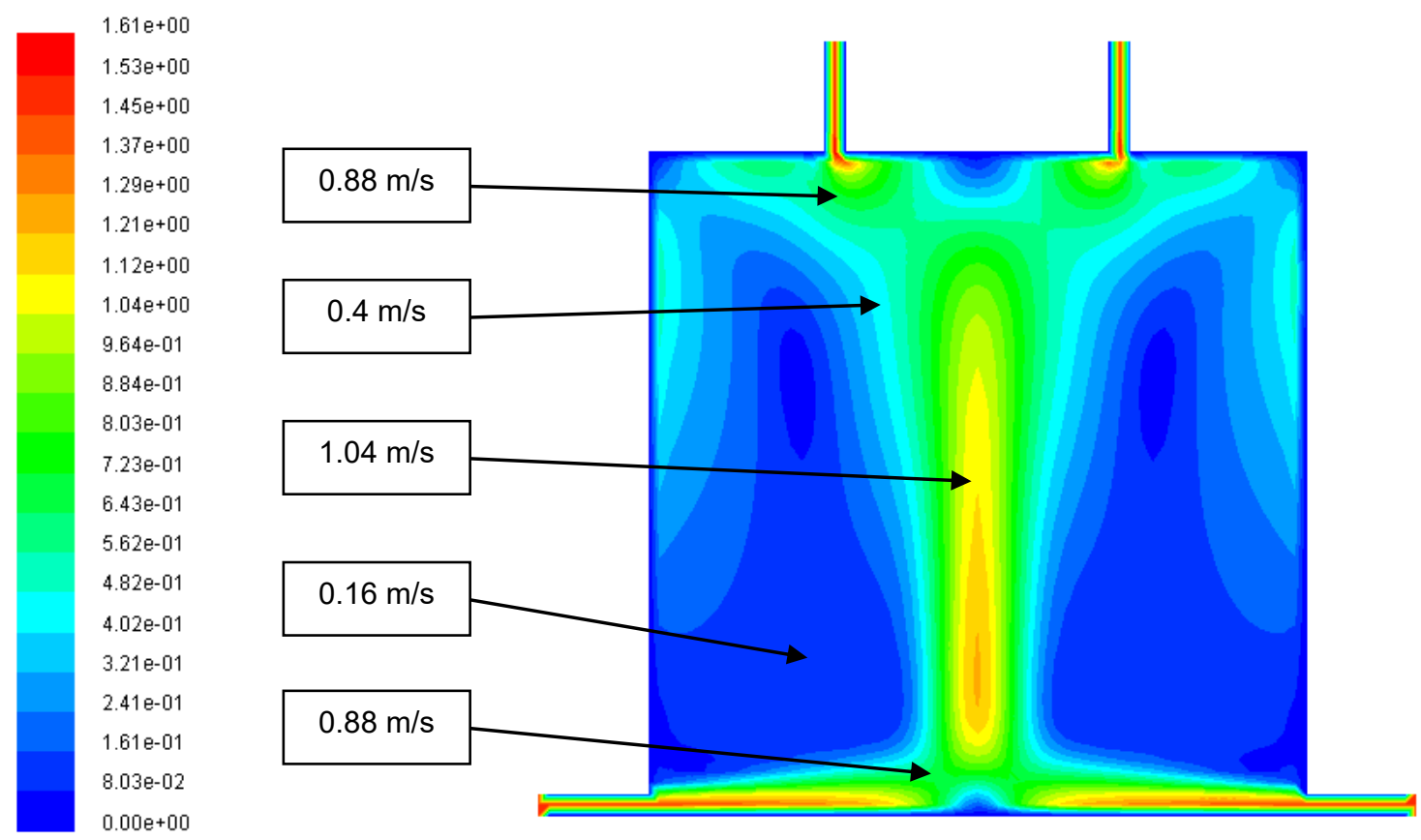

Figure 14 - Contours of velocity magnitude $(\mathrm{m} / \mathrm{s})$

The temperature results Figure 15, shown as contours, follow the same route as the airflow and velocity. Maximum temperature flows through the centre of the kiln.
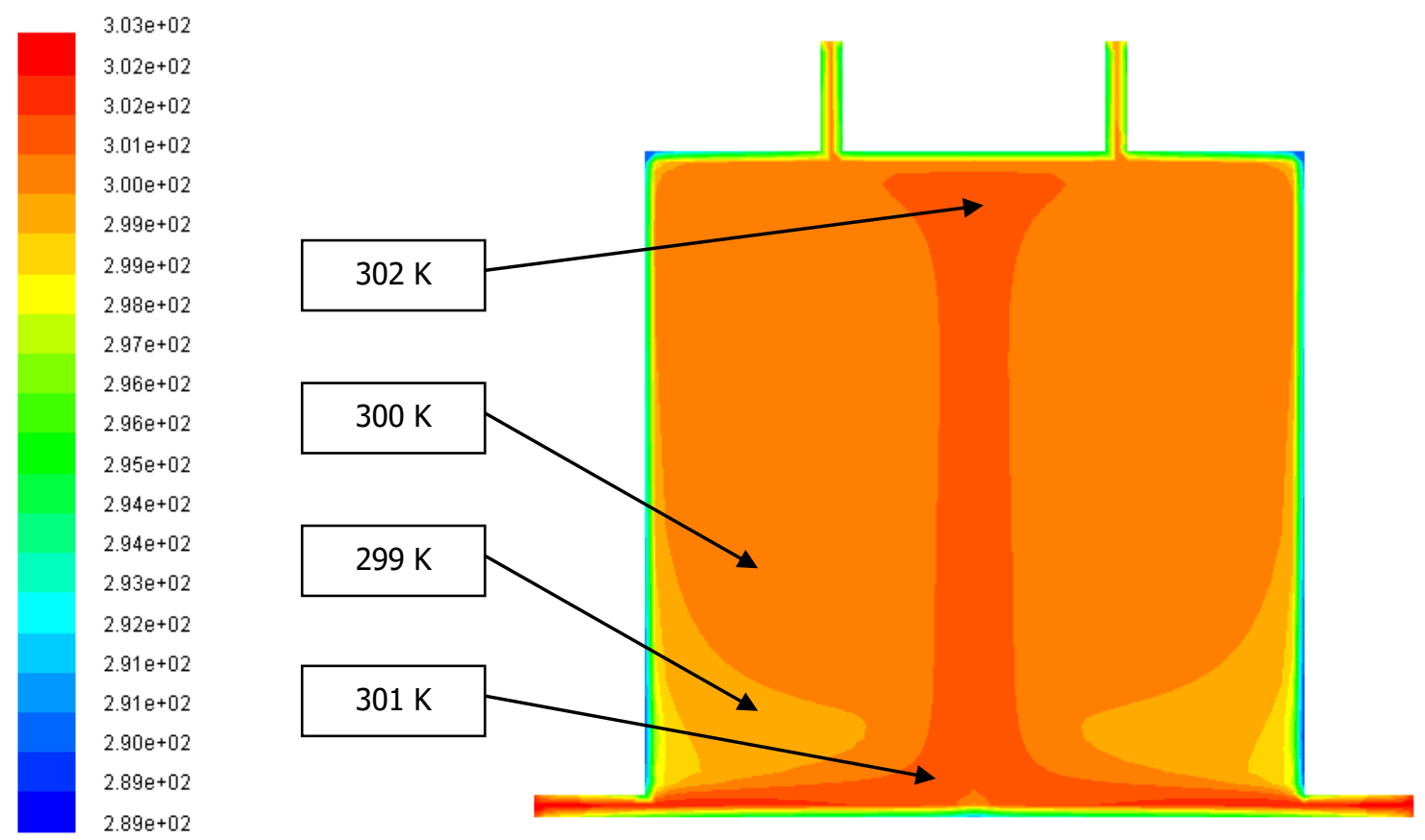

Figure 15 - Contours of total temperature (K) 
The three designs are compared in Table 4. Here the inlet and outlet temperatures are compared to establish the impact on heat loss through each design modification.

Table 4 Comparison of modified kiln results

\begin{tabular}{|l|l|l|l|}
\hline \multirow{2}{*}{ Kiln Designs } & \multicolumn{2}{|l|}{ Temperature Distribution (K) } & \multirow{2}{*}{ Temp Diff } \\
\cline { 2 - 3 } & Inlet & Outlet & \\
\hline Original Design & 303 & 301 & 2 \\
\hline a) Cross Ventilation & 303 & 298 & 5 \\
\hline $\begin{array}{l}\text { b) Cross ventilation with Roof } \\
\text { Extract Outlets }\end{array}$ & 303 & 303 & 0 \\
\hline
\end{tabular}

\subsection{Discussion}

Table 3 highlights the UK's Meteorology results taken from a Sheffield weather station for 2008. The table highlights the effective period of time throughout the year in which the kiln shall be able to optimise the sunshine hours of the UK climate, with the potential of warming the inlet air temperature. The table also considers the maximum temperatures recorded throughout the year in which the kiln through conduction of the lightweight structure shall be able utilise the surrounding air temperature to warm the internal air temperature of the kiln.

From the initial study it is clear from the temperature contours of the original kiln design, shown in Figure 8, there are temperature deviations, or short circuits in the flow domain. This is undesirable as the loaded kiln would dry unevenly and be more time consuming to the user.

The meteorology results for Sheffield demonstrated that 9 out of 12 months of the year recorded over 100 hours sunshine hours per month and for 6 months out of the year where the sunshine hours are recorded highest the minimum temperature did not drop below 10 ${ }^{\circ} \mathrm{C}$. The low heat loss of the kiln highlights the enormous potential of the lightweight structure to optimise the suns potential within a temperate climate such as the UK. 
A comparison of the velocity contours from the original design and cross ventilated design, Figure 8 and 11 respectively, it can be seen that a more even, symmetrical flow about the vertical axis has been created. As the kiln is centrally loaded this symmetrical air distribution is highly desirable. A comparison of Figure 11 with Figure 14, the cross ventilation with roof extract design shows a similar symmetrical distribution.

The temperature contours of the original kiln design, shown in Figure 9, demonstrate a number of temperature deviations, or short circuits in the flow domain. This is undesirable as the loaded kiln would dry unevenly and be more time consuming to the user.

The temperatures contours of the cross ventilated kiln, Figure 12, show a more evenly distributed temperature in comparison to Figure 9. However the temperature difference across the kiln (bottom to top) has increased. This uneven temperature distribution would have varying consequences dependant on the kiln loading and creates further unpredictability to the user.

Finally the temperature contours in the cross ventilated kiln with roof extracts, Figure 15, shows an evenly distributed temperature similar to Figure 12. However in this design the kiln now demonstrates an even distribution across the kiln (bottom to top) with a minimal temperature difference of 1 degree Kelvin.

Moreover a comparison between the three designs, shown in Table 4, demonstrates that the cross ventilated kiln with roof extracts is more capable of reducing temperature loss within the flow domain.

\subsection{Conclusion}

This work has show the potential of a passive solar kiln within the UK without the integration of mechanical assists. The results have shown some areas which may be optimised through redesign to eliminate short-circuiting, thus optimising the design of the kiln to further improve the key performance indicators. The optimised kiln has the potential to effectively utilise the free energy generated from the sun for longer sustained periods of the year, dramatically lowering the need for non renewable energy sources. The authors conclude that the modified kiln design, incorporating cross ventilation with roof extracts enhances the capabilities and performance of the solar kiln, through reduced heat loss and even temperature distribution. Thus the load drying times may be reduced and kiln capacity increased. Having established the optimised basic design future work will focus on incorporating solar loading techniques to improve operational times. 


\section{Acknowledgements}

The authors would like to acknowledge the support and assistance of Nick Parsons and his team at the Sustainability Centre, Heeley City Farm Sheffield, registered charity number 1111482.

\section{References}

Mujumdar, S, Arun (2006). Handbook of industrial drying, Ed $3^{\text {rd }}$. Taylor \& Francis Group Bentayeba, F., Bekkiouia,N. and Zeghmatib, B. (2008). Modelling and Simulation of a Wood Solar Dryer in a Moroccan Climate. Renewable Energy, 33, 501-506.

Haque, M (2002). Modelling of solar kilns and the development of an optimised schedule for drying hardwood timber - Chapter 1 . The University of Sydney

De Vore, J. B., Denny, G. S. and Harper, T. S.(1999). A Commercially Viable Solar Wood Drying Kiln System. Drying Technology, 17:1, $271-283$.

Fuwape, I., and Fuwape, J. (1995). Construction and Evaluation of a Timber-drying Solar Kiln. Bioresource Technology, 52, 283-285. Elsevier

Hughes, B. R., Abdul Ghani, S. A. A. (2008). Investigation of a Windvent Passive Ventilation Device Against Current Fresh Air Supply Recommendations. Energy and Buildings, 40, 1651-1659.

Luna, D et al (2009). Solar timber kilns: State of the art and foreseeable developments. Journal. Renewable and Sustainable Energy Reviews, Volume 13, Pages 1446-1455. Elsevier

FLUENT. Fluent user manual 6.2. Fluent Incorporated.

CHUNG, T. J. (2002). Computational fluid dynamics. Cambridge, University press.

JIANG, Y., ALLOCCA, C. and CHEN, Q. (2004). Validation of CFD simulations for natural ventilation. International journal of ventilation, 2 (4), 359-370.

Lomas, K. J. (2007). Architectural Design of an Advanced Naturally Ventilated Building Form. Energy and Buildings, 39, 166-181.

Chen, H., Hernandez, C. E., Huang, T. 2005. A study of the drying effect on lemon slices using a closed-type solar dryer. Solar Energy 78, 97-103. 
Ferreira et al., 2008. Technical feasibility assessment of a solar chimney for food drying. Solar Energy 82, 98-205.

Forson et al. 2007. Modelling and experimental studies on a mixed-mode natural convection solar crop-dryer. Solar Energy 81, 346-357.

Hossain, M.A.; Bala, B.K.. 2007. Drying of hot chilli using solar tunnel drier. Solar Energy 81, 85-92.

Jairaj, K.S. ; Singh, S.P., Srikant, K. 2009. A review of solar dryers developed for grape drying. Solar Energy 83, 1698-1712.

Sethi, V.P.; Arora , S. 2009. Improvement in greenhouse solar drying using inclined north wall reflection. Solar Energy 83, 1472-1484. 